AIP Applied Physics

\title{
Annealing of ion implanted silver colloids in glass
}

\author{
R. A. Wood, P. D. Townsend, N. D. Skelland, D. E. Hole, J. Barton et al.
}

Citation: J. Appl. Phys. 74, 5754 (1993); doi: 10.1063/1.354194

View online: http://dx.doi.org/10.1063/1.354194

View Table of Contents: http://jap.aip.org/resource/1/JAPIAU/v74/i9

Published by the American Institute of Physics.

\section{Related Articles}

Theory of liquid crystalline micelles

J. Chem. Phys. 138, 034902 (2013)

Improved luminescence from CdSe quantum dots with a strain-compensated shell

Appl. Phys. Lett. 102, 023106 (2013)

Relationship between neighbor number and vibrational spectra in disordered colloidal clusters with attractive interactions

J. Chem. Phys. 138, 12 A525 (2013)

Entangled triblock copolymer gel: Morphological and mechanical properties

J. Chem. Phys. 138, 024908 (2013)

Communication: A simple analytical formula for the free energy of ligand-receptor-mediated interactions JCP: BioChem. Phys. 7, 01 B401 (2013)

\section{Additional information on J. Appl. Phys.}

Journal Homepage: http://jap.aip.org/

Journal Information: http://jap.aip.org/about/about_the_journal

Top downloads: http://jap.aip.org/features/most_downloaded

Information for Authors: http://jap.aip.org/authors

\section{ADVERTISEMENT}

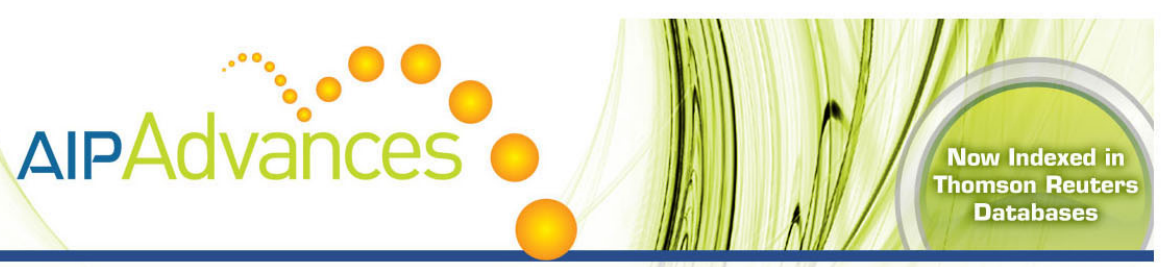

\section{Explore AIP's open access journal: Rapid publication \\ - Article-level metrics \\ - Post-publication rating and commenting}




\title{
Annealing of ion implanted silver colloids in glass
}

\author{
R. A. Wood, P. D. Townsend, N. D. Skelland, D. E. Hole, and J. Barton \\ Department of Mathematical and Physical Sciences, University of Sussex, Brighton BN1 9QH, \\ United Kingdom \\ C. N. Afonso \\ Instituto de Optica, Consejo Superior de Investigaciones Cientificas, Serrano 121, Madrid 28006, Spain
}

(Received 22 March 1993; accepted for publication 12 July 1993)

Silver colloids have been formed by ion implantation in float glass. Subsequent annealing methods alter the size distribution and optical reflectivity of the colloids. Furnace anneals and rapid flame heating convert large colloids into smaller units but excimer laser annealing appears to cause a dissolution of silver into the glass network.

\section{INTRODUCTION}

Surface modification of insulating materials can often be accomplished by ion beam implantation and the resulting changes are of interest both for purely academic studies of ion beam interactions and imperfections and for studies of potential device applications. ${ }^{1-3}$ Although the literature for ion implanted insulators is not as extensive as for semiconductors and metals, there are, nevertheless, applications as diverse as the fabrication of optical waveguides and waveguide lasers: $:^{4,5}$ definition of optical and electrical pathways on insulating surfaces; production of glass layers with optical nonlinearities ${ }^{6}$ and large values of $\chi^{(3)}$; and control of antireflective layers ${ }^{7}$ and blue biased rearview car mirrors. ${ }^{8}$ Several of these examples require a controlled production of metallic colloids buried in the surface layer of glass. The present work is part of an attempt to gain control over the size and depth distribution of such metal colloids.

Ion implantation of metal ions into insulating materials such as glass, quartz, or $\mathrm{LiNbO}_{3}$ results in metallic colloid formation from the implanted impurity ions. Examples include $\mathrm{Ag}, \mathrm{Au}$, and $\mathrm{Cu}$ implants. ${ }^{9-13}$ Other types of damage generation using ionizing radiation or thermal diffusion can similarly introduce high defect densities and subsequent colloid precipitation of metallic lattice ions as, for example, in $\mathrm{CaF}_{2}$ (Ref. 14) or $\mathrm{Al}_{2} \mathrm{O}_{3}$ (Ref. 15). Since ion implantation results in both impurity additions and extensive radiation damage, the implants may produce a mixture of colloids comprised of more than one type of metal. Indeed, recent electron microscopy data have revealed separate regions of impurity and intrinsic colloids following Ag implant in glass. ${ }^{16}$

Excess silver introduced into glass, either by thermal or ion implantation routes, can lead to colloid production. Optical studies of silver implanted glasse ${ }^{11,12}$ demonstrate the presence of silver colloids. These colloids have a distribution that varies in size and density with their depth in the substrate. The distributions are highly sensitive to implantation conditions and can be modified by thermal treatments. Figure 1 shows the evolution of reflectance with dose of a typical silver implant into float glass of the type used in the current annealing experiments. Whereas the inclusion of uniformly sized metal as a clearly resolved absorption or reflectance band, ${ }^{14}$ the implanted colloids display a broad blue band. The TEM data provide details of typical colloid size variations with implant depth in which the layer of largest colloids are almost touching one another. The complexity of depth distribution results in dose dependent changes in the reflectivity data, including evidence of shoulders on the main peak and also differences between reflectivity monitored from the implanted and the reverse faces. ${ }^{12}$ These features are a result of reflection from different layers of silver colloids of predominantly different sizes combined with optical absorption within each layer.

Three thermal treatments, involving processing time scales that differ by several orders of magnitude, have been included in the present work. They are furnace, rapid thermal annealing, and laser pulse annealing. The last technique has the advantage of driving the surface to high temperature while the bulk and substrate regions remain virtually unheated; in addition, it minimizes the role of diffusion controlled processes when short (ns) pulses are used. While laser irradiation has been widely and successfully used to anneal ion implanted semiconductors and metals, ${ }^{17-20}$ literature on an insulator is very restricted ${ }^{21}$ and has been mainly concerned with laser damage studies. ${ }^{22}$ However, a recent example ${ }^{23}$ includes the treatment of ion implanted $\mathrm{K}$ in $\mathrm{MgO}$.

\section{EXPERIMENTAL DETAILS}

The samples used for the annealing studies were standard float glass [from the Societa Italiana Vetro (SIV)] into which silver ions were implanted at $60 \mathrm{keV}$ to a dose of $4 \times 10^{16}$ ions $/ \mathrm{cm}^{2}$ at room temperature. A large single sample $(10 \times 10 \mathrm{~cm})$ was cut into smaller pieces for the laser and the rapid thermal annealing experiments and another sample of similarly the same implant conditions was used for the furnace annealing. The latter sample had a slightly lower initial reflectance. For the thermal treatments the large sample was cut into pieces of $2 \times 2 \mathrm{~cm}$, whereas for the laser studies, different sections of a large piece were separately illuminated.

Thermal treatments were made by three distinct approaches. One was the conventional furnace anneal in which the samples were ramped up to temperature over a 


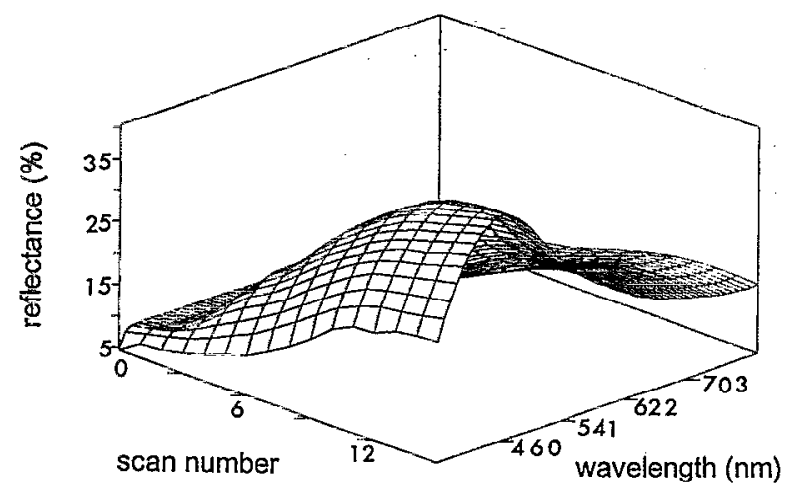

FIG. 1. An example of the reflectivity changes with ion dose during Ag ion implants of float glass. The grid units correspond to dose increments of $0.53 \times 10^{16} \mathrm{ions} / \mathrm{cm}^{2}$.

period of a few minutes and held at fixed temperature for $10 \mathrm{~min}$. The cooling period ranged from 1 to $5 \mathrm{~min}$, depending on the maxinum temperature. Rapid thermal annealing used a propane flame to heat the glass surface. This approach produced a rapid temperature rise and total heating times were from 10 to $45 \mathrm{~s}$. The surface temperature of the glass during flame treatment was measured to be near $700^{\circ} \mathrm{C}$. Cooling was more rapid than in a furnace as the bulk temperature was low and was measured to be less than $200^{\circ} \mathrm{C}$. The third approach was to use excimer laser pulses that heated the colloid rich surface layer of the sample within $12 \mathrm{~ns}$. An ArF (193 nm) excimer laser was partially focused on the sample to yield an energy density of $85 \mathrm{~mJ} / \mathrm{cm}^{2}$. Several pulses, up to a maximum of 500 , were accumulated in the various areas of the specimen at a repetition rate of $10 \mathrm{~Hz}$.

Optical reflectivity data were recorded with Monolight optical systems, either in situ during the implantation, as in Fig. 1, or after subsequent annealing. The in situ arrangement gave slightly less accurate reflectivity values.

Depth analysis of the silver was made using Rutherford backscattering spectrometry (RBS) with He ions at $1.8 \mathrm{MeV}$.

\section{RESULTS AND DISCUSSION}

The three approaches gave very different results, as assessed by the optical reflectivity, and the data are compared in Fig. 2. No transmission electron microscopy data are available for this set of experiments, but the RBS data show that the higher temperature furnace treatments led to a loss of silver. There is a marked decrease in the amount of silver retained (about $30 \%$ ) after heating above $350^{\circ} \mathrm{C}$ (lower temperature data are not shown). This is followed by a slight loss at each subsequent stage up to $650^{\circ} \mathrm{C}$ and, finally, a substantial fall after the $700^{\circ} \mathrm{C}$ treatment. There was no obvious silver in-diffusion determined by the RBS depth profile although the FWHM finally reduced it by $30 \%$. When comparing the reflectivity of the as-implanted sample to that obtained after furnace annealing, it can be observed in the upper part of Fig. 2 that annealing moves the reflectivity maxima from the $470 \mathrm{~nm}$ region towards
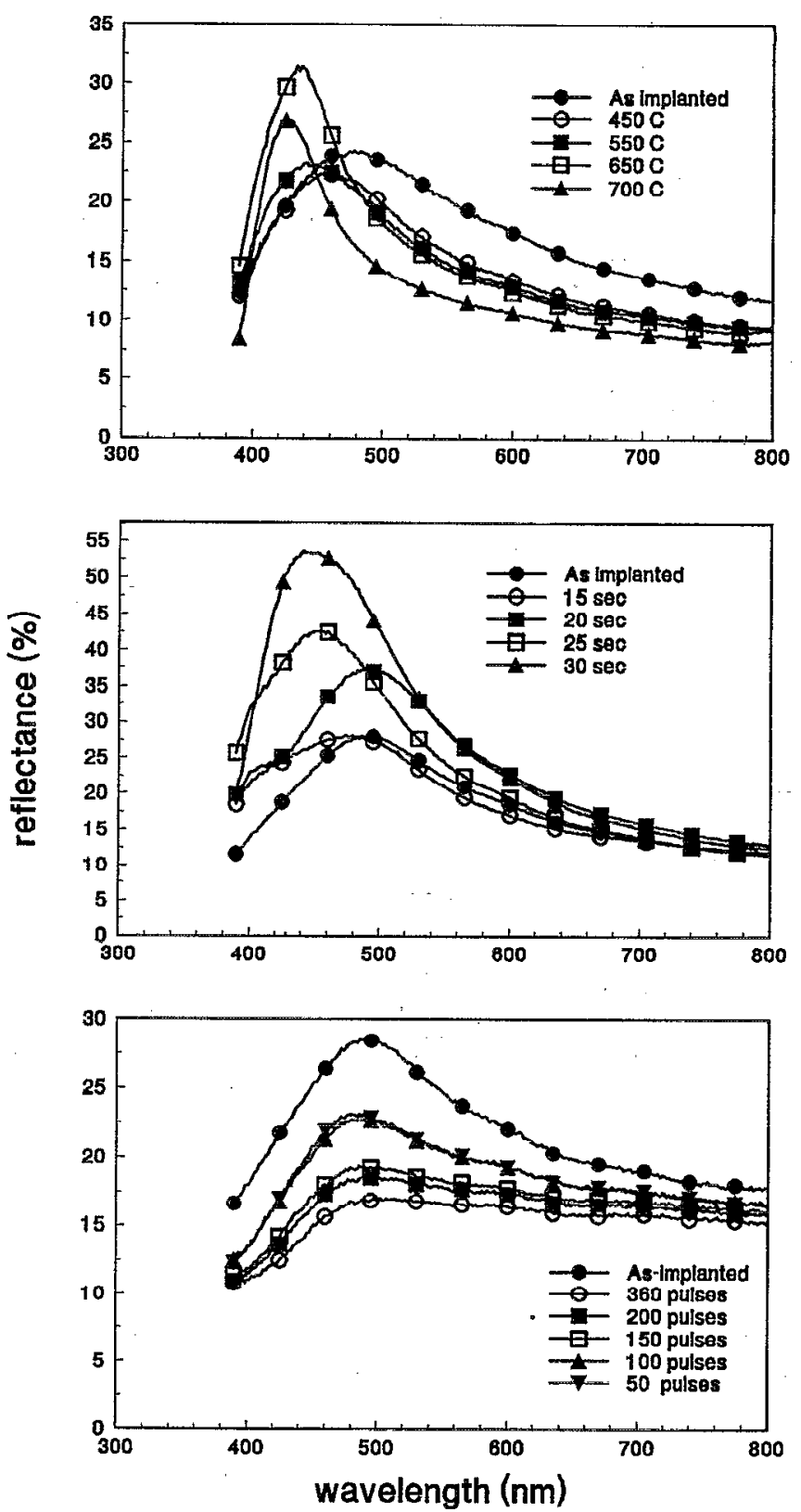

FIG. 2. Movement of the silver colloid reflectivity peak as the result of annealing. Upper curves-after furnace annealing; middle curves-after flame annealing; and lower curves-after excimer laser anneals.

the $420 \mathrm{~nm}$. This is consistent with the breakup of large colloids into smaller units according to standard colloid absorption band models. The optical signal is a function of colloid concentration times its volume, thus a change from large to small units gives an increase in total colloid concentration. This produces an increase in the shorter wavelength reflectivity band as seen in the figure. The increase in the blue response, due to breakup of large colloids into smaller units, is offset by increased silver loss after $700^{\circ} \mathrm{C}$ heating.

The rapid thermal annealing produced by a gas flame leads to negligible silver loss. As demonstrated by the middle set of optical data in Fig. 2, there is some similarity 
with the furnace treatment. The reflectivity peak rises rapidly and moves from near $500 \mathrm{~nm}$ towards $450 \mathrm{~nm}$. Negligible loss of silver is recorded by RBS even after the longest flame treatment. More extended flame treatment caused the surface to melt.

The laser pulse annealing follows the same pattern as the low temperature furnace or flame annealing in terms of RBS data, in that there is no evidence of silver loss, nor, in this case, loss by diffusion (i.e., RBS only indicated silver loss or migration for furnace annealing above $350^{\circ} \mathrm{C}$ ). The RBS data indicate that the projected ion range and the mean depth remain near 20 and $25 \mathrm{~nm}$, respectively. Optically, the laser anneal data of Fig. 2 show no significant shift in the peak wavelength as would be expected for conversion from large to small colloids. Instead, the intensity of the broad band observed in the as-implanted samples simply decreases with the number of laser pulses. There are a number of possibilities of why this may happen. For example, the silver may be converted into isolated atomic silver that is bonded into the lattice of the glass by restructuring of the glass network. A less dramatic possibility is that the large colloids may separate into such small units that they no longer interact as colloids. It should be noted that even at long wavelengths the overall reflectivity is higher than that of the original silicate glass. This is expected of a new, higher density, glass layer that includes ions (Ag) of high polarizability. Hence the reflectivity data suggest that all the large silver colloids are dispersed into such small units that colloid type reflection is no longer appropriate.

\section{SUMMARY}

One may modify the state of the silver colloid size distribution by several approaches that lead to different final colloid size distributions. The most unexpected result comes from laser annealing, which apparently destroys large colloids but does not generate small ones. This sug- gests that the silver has been atomically incorporated within the glass structure. The data are interesting for potential applications such as optical nonlinearity or controlled reflectivity since optical properties depend on the colloid structures.

\section{ACKNOWLEDGMENT}

We wish to thank the Societa Italiana Vetro for financial support and encouragement.

${ }^{1}$ P. D. Townsend, Rep. Prog. Phys. 58, 501 (1987).

${ }^{2}$ R. A. Weeks, Mater. Sci. Tech. 9, 331 (1991).

${ }^{3}$ P. D. Townsend, P. J. Chandler, and L. Zhang, Optical Effects of Ion Implantation (Cambridge University Press, Cambridge, in press).

${ }^{4}$ P. J. Chandler, L. Zhang, and P. D. Townsend, Solid State Phenom. 27, 129 (1992)

${ }^{5}$ A. Polman, D. C. Jacobson, D. J. Eaglesham, R. C. Kistler, and J. M. Poate, J. Appl. Phys. 70, 3778 (1991).

${ }^{6}$ K. Becker, L. Yang, R. F. Haglund, R. H. Magruder, R. A. Weeks, and R. A. Zuhr, Nucl. Instrum. Methods B 59/60, 1304 (1991).

${ }^{7}$ J. Koch, UK Patent No. 677,784 (1947).

${ }^{8}$ P. D. Townsend and L. Massarelli, US Patent No. 07,618,507 (1991).

${ }^{9}$ G. W. Arnold and J. A. Borders, J. Appl. Phys. 48, 1488 (1977).

${ }^{10} \mathrm{M}$. Rahmani and P. D. Townsend, Vacuum 39, 1157 (1989).

${ }^{11}$ H. Hosono, Y. Abe, and N. Matsunami, Appl. Phys. Lett. 60, 2613 (1992).

${ }^{12}$ L. C. Nistor, J. Van Landuyt, J. Barton, D. E. Hole, N. D. Skelland, and P. D. Townsend, J. Non-Cryst. Solids (in press).

${ }^{13}$ H. Hosono. H. Fukushima, Y. Abe, R. A. Weeks, and R. A. Zuhr, J. Non-Cryst. Solids 143, 157 (1992).

${ }^{14}$ V. M. Orera and R. Alcala, Phys. Status Solidi A 38, 621 (1976).

${ }^{15}$ E. R. Hodgson, Radiat. Eff. 119/121, 827 (1991).

${ }^{16}$ L. C. Nistor (unpublished).

${ }^{17}$ G. Sorensen, Nucl. Instrum. Methods 186, 189 (1981).

${ }^{18}$ D. Hoonhout and F. W. Saris, Radiat. Eff. 66, 43 (1982).

${ }^{19}$ Laser Annealing of Semiconductors, edited by J. M. Poate and J. W. Mayer (Academic, New York, 1982).

${ }^{2 n}$ M. Von Allmen, Laser Beam Interactions with Materials (Springer, Berlin, 1987).

${ }^{21}$ U. B. Ramabadran, H. E. Jackson, and G. C. Farlow, Appl. Phys. Lett. 55, 1199 (1989).

${ }^{22}$ A. H. Guenther and T. W. Humphreys, SPIE 401, 247 (1983).

${ }^{23}$ J. Rankin, P. Thevenard, L. J. Romana, L. A. Boatner, C. W. White, C. J. McHargue, and L. L. Horton, Surf. Coatings Tech. 51, 471 (1992). 